\title{
Mill Ownership and Farmer's Cooperative Behavior: The case of Costa Rica Coffee Farmers*
}

\author{
Astrid Hopfensitz and Josepa Miquel-Florensa \\ Toulouse School of Economics
}

September, 2015

\begin{abstract}
We analyze how Costa Rican coffee farmer's behavior in an experimental public good game depends on the type of mill where the farmers sell their coffee (Cooperative vs. privately owned mills), and on the background of their game partners (partners selling to same type of mill or not). We find that cooperative farmers do not display more public good orientation than private market farmers when playing with partners from the same type of mill. However, while farmers selling to private mills make no difference with respect to the background of partners, farmers selling to cooperatives significantly decrease contributions when paired with non-cooperative members. Finally, we study how self-selection into a mechanism that punishes the lowest contributors affects contributions both inside the group and with partners of the opposite background, and show that this increases contributions in the games played with farmers selling to different mill type.
\end{abstract}

JEL classification numbers: C92, O13, Q13

Keywords: Cooperatives, Coffee, Institutions, Public Good, Experiment, Costa Rica

\footnotetext{
*We would like to thank CATIE (Centro Agronomico Tropical de Investigacion y Ensenanza) for their hospitality while the study was performed. Special gratitude goes to Juan Robalino and Maria Angelica Naranjo for their invaluable logistic support on the field, and to Itsaso Hormaeche for her excellent assistance. We thank for their comments Stephane Straub, Peter Martinson, Francisco Alpizar, Rocco Macciavello, and seminar participants at UAB, TSE, Universidad de Oviedo and the Santa Fe Institute and workshop participants at the Montpellier workshop on field experiments and the TIES workshop in Toulouse. Financial help through a ANR research grant (2010 JCJC 1803 01) is gratefully acknowledged.
} 


\section{Introduction}

Social interactions and trust among farmers have been documented as crucial for farmer's well being and for the design of support programs. For example, informal insurance mechanisms (Fafchamps and Lund, 2003; Karlan et al., 2009), adoption of new farming techniques (Conley and Udry, 2010) or take-up of insurance products (Karlan et al., 2014) have been shown to be closely related to information about and trust in neighbor's behavior.

We focus on the case of coffee, in which mill's buying locations are focal for farmers' social interactions and two types of mill ownership coexist (privately owned and cooperatives). While cooperatives are often viewed as institutional structures that enforce social and fair behavior, scientific evidence of the existence of such effects is scarce. Through the analysis of contributions to an experimental public good performed with coffee farmers in Costa Rica, we analyze how farmer's behavior depends on the type of mill to which they sell their coffee (cooperative vs. privately owned mills). We additionally vary the background of the partners they are paired with in the game (partners selling to same vs. a different type of mill) and study how self-selection into a mechanism that will punish the lowest contributors in the group affects contributions.

Specifically, we address the following general questions: (1) Do the two types of farmers react differently when interacting with farmers selling to the same type of mill vs. the other type? and (2) In case a mechanism could be established to punish free-riders, which group of farmers would be more willing to implement such a mechanism, and how would it affect contributions? The answer to these questions allows us to analyze whether belonging to a participatory institution (cooperative) has a differential effect on the contributions inside the mill compared to farmers selling to private mills. Our main result is that farmers selling to cooperative mills cooperate less with game partners that do not sell to a cooperative mill, and they respond more to the introduction of control mechanisms.

Costa Rica is an good setting to answer these questions. Land distribution is quite homogeneous among many small farmers, and historically the relationship of farmers with all types of mills has been peaceful (Paige, 1997). The role of ICAFE, the coffee board, is to regulate the distribution of profits along the value chain with no intervention on the farmer's choice of where to deposit their cherries. ${ }^{1}$ We focus on behavior by coffee farmers that are active members of a cooperative and contrast their choices to farmers that are selling to the privately owned mills. The peculiarity of our sample is that almost all farmers have belonged to a cooperative at some point in their lives, and for different circumstances (mainly financial failure of the institution), part of them got involved in selling to the private sector. We acknowledge that the coexistence

\footnotetext{
${ }^{1}$ The coffee boards of other countries, for example Colombia, have strong relationship with cooperatives, using them as implementing arms for many of the National programs. In Costa Rica, the relationship of the coffee board is equal for all types of mills.
} 
of the two types of mills in the same areas raises selection issues into each type of mill. ${ }^{2}$ On the other hand, this coexistence offers the possibility to study how the type of mill, farmers in a given area sell to, affects behavior with farmers selling to either type of mill present in their community.

We structure the presentation of our results along three main parts: (1) Do the contributions to the public good game differ between farmers belonging to the two types of mills when they play with partners selling to the same type of mill? (2) What is the relationship between the groups, i.e. are contributions sensitive to the background of the partners when farmers of different types are matched? and (3) In which settings (which type of mill and against which partner's background) will farmers be willing to add a mechanism to the public good game that punishes free-riders and what will be their reaction to it when added? Finally, as an external validity check, we study how cooperative farmers' side-selling behavior and the cooperative characteristics (fair trade label) are correlated with experimental contributions.

With respect to the first question, both cooperatives and privately owned mills offer farmers a forum of interaction. The main difference between the two types of mills is that cooperatives provide an institutional structure that allows its members to 'cooperate' for joint social or financial benefits. We find that contributions in a public good game played with partners from the same type of mill do not differ significantly across the two types of mills. This result shows that the extra-involvement intrinsic to the cooperative structure does not translate into more collaborative behavior.

When looking at the reaction to the background of partners, we find that cooperative farmers strongly react to it, significantly decreasing contributions when paired with farmers selling to private mills. For private market participants, on the other hand, we do not find significant reaction to the background of partners. We hypothesize that this result may be due to a 'negative stigma' attached to private mills from the point of view of cooperative farmers. This is supported by the fact that cooperative farmers reporting at least some side-selling make a significantly smaller difference between the groups than cooperativists not reporting side-selling.

After analyzing the behavior on the standard public good game, we offer participants the possibility to introduce to the game a mechanism that penalizes free-riders. The role of this scheme is to implement a fee on the lowest contributor to the game, and revert part of this fee to the common pool. We find that adoption of this scheme is very high across groups and partners: from $93 \%$ for farmers selling to private mills when matched with cooperativists to $73 \%$ for cooperative farmers playing with private market participants. While the introduction of the scheme does not have a significant effect when matched with partners selling to the same type of mill, its effect is large (increase of 3 contribution points over 10 feasible) when matched with partners of a different background.

\footnotetext{
${ }^{2}$ This lack of zoning prevent us from using a discontinuity analysis as in Sukhtankar (2015).
} 
In an extension we discuss the external validity of abstract game behavior by correlating free-riding in the abstract public good with real world side-selling. We further investigate whether members of cooperatives that hold the Fair Trade label (introducing additional rules to the cooperatives) differ in abstract game behavior. We find that side-selling has a negative effect on public good contributions and that farmers in cooperatives holding the Fair Trade label contribute significantly less independently of the background of their partners.

The paper contributes to several strands of the literature. First, cooperatives are a traditional cash crop structure in developing countries and have been extensively studied. Banerjee et al. (2001) and Sukhtankar (2012) have analyzed how land distribution and political pressure affects their governance structure and outcomes for farmers, and Simmons and Birchall (2009) have focused on their lack of success in increasing well being of rural poor. We add to this literature by checking how cooperatives may affect farmers' collaborative behavior, and cooperative farmer's choice of institutional mechanisms in that context.

Second, the paper adds to the literature making use of experimental economics to measure cooperative behavior and social capital (e.g. Karlan, 2005; Fehr and Leibbrand, 2011). Studies of in-group versus outgroup behavior suggest that contributions are higher when paired with participants from one's own group than with out-group members (Tajfel and Turner, 1979; Bernhard et al, 2006; Goette et al., 2006). Differences in pro-sociality of different types of groups have also been investigated by Banuri and Keefer (2012), comparing the behavior of government officials in Indonesia with private sector participants. Experimental work on fishing cooperatives (Carpenter and Seki, 2011; Gelcich et al., 2012) show that special institutional structures as pooling of fish and involvement of well organized unions, can increase contributions in laboratory settings. Our contribution is to look at behavior related to interactions with the own vs. a different group, where one of the groups is composed of farmers from cooperatives and the other of farmers selling to private mills. Cooperatives add benefits (credit, supplies and public goods as health and education programs) but also costs (assemblies, exclusivity restrictions on sales) to the social interactions taking place at mills. One limitation of our setting, discussed at the end of this paper, is that we cannot control for selection into the two groups. While this is a limitation, the coexistence of both types of mills at the same location is what allows us to compare behavior of farmers with respect to own and the other type of mills.

Finally, we provide some insight related to the sustainability of both types of institutions. Indeed, sideselling, even if it violates the cooperative's exclusivity clause, is common, and has given raise to a growing literature on loyalty of members to the cooperatives (e.g., Casaburi and Macchiavello, 2015). In our extension, we study how farmers that declare to side-sell part of their production and the certifications of the institution affect the farmers' collaborative behavior.

The structure of the paper is as follows. In Section 2 we describe the setting in which the study was 
performed and the details of the sample. Section 3 presents the structure of the study. In Section 4, we present the results. Section 5 presents extensions to analyze how real world behavior and cooperative characteristics correlate with contributions. Section 6 concludes.

\section{Background and Data}

\subsection{Coffee market in Costa Rica}

Coffee is the third most important agricultural export product in Costa Rica, after bananas and pineapples. ${ }^{3}$ In Costa Rica, coffee commercialisation is at the hands of the private sector, with strong supervision by the state through the Instituto del Cafe de Costa Rica (ICAFE). ${ }^{4}$

At the first stage of the coffee value chain, coffee farmers have the choice to bring their produce to any mill with the constraint of bringing the cherries to the mill within twenty-four hours from collection. In all districts (sub-locations) the farmers can go to two types of mills: privately owned and cooperatives. The sales to both types of mills, with respect to payment terms and prices paid, are subject to identical ICAFE regulations. However, cooperative mills have membership requirements as well as exclusivity clauses specific to the cooperative institution.

Cooperativism is important in the Costa Rican culture and economy: $37 \%$ of the economically active population is directly or indirectly related to a cooperative. From the estimated 52500 farmers growing coffee in Costa Rica, 26881 are members of cooperatives, which represent $37 \%$ of the country's production. ${ }^{5}$ As presented in Paige (1997), cooperatives have historically had an important role on the coffee industry in Costa Rica. All cooperatives have the same governance structure as regulated by the Costa Rica cooperative laws. The internal regulation for each of the cooperatives establishes the roles and responsibilities of the cooperative members. Among other, these regulations establish the obligation of members to bring all their produce to the cooperative, and the vote and voice rights attached to cooperative membership. Cooperatives offer their members multiple benefits, like credit for inputs and training in farming techniques.

\subsection{Sample characteristics}

We conducted our study with coffee producers selling to each type of mill: private and cooperative. The mills where the study was performed are located at the high altitude mountains and valleys of the Tarrazu

\footnotetext{
${ }^{3}$ Coffee represented $16.62 \%$ of the agricultural exports in 2012, $12.55 \%$ in 2013 and $10.99 \%$ in 2014 . Source: Promotora del Comercio Exterior de Costa Rica, Estatisticas de Comercio Exterior.

${ }^{4}$ The ICAFE is regulated by the 'Ley 2762 del 21 de junio de 1961'. For more details, see: www.icafe.go.cr. On this site, the ICAFE is defined as 'una entidad pública de carácter no estatal que promueve la actividad cafetalera nacional'(a non-governemental public institution that promotes the national coffee activity).

${ }^{5}$ Sources: INFOCOOP, III Censo Nacional Cooperativo (2008) and Coocafe.
} 
region, and at the lower altitude volcanic region of Turrialba. The Tarrazu region, in Los Santos District, represents $30 \%$ of the Costa Rican coffee production, and is the country's most traditional coffee region, with the majority of farmers not having alternative sources of income. The three cooperatives and one of the private mills that we visited are located in the Tarrazu Region. The second private mill is located in the Turrialba region. Detailed information about the different areas can be found in Appendix A. We observe no major differences between the areas involved in this study concerning land tenancy or use. The selected cooperatives and private mills are similar in terms of age and competition from other mills in the area. Two of the three selected cooperatives were holding the Fair Trade label at the time of the study.

Farmers were contacted by the cooperative or private mill respectively, to ask their voluntary participation in a scientific study. Response rates were approximately $70 \%$. The study was run in groups of 15 - 20 farmers at the cooperative meeting room and at adapted spaces at the private mills and lasted for approximately 2 hours. Average age of participants was 47 years and about $10 \%$ of participants were women. Summary statistics of the participants can be found in Table 1.

Our aim is to compare the two groups in terms of behavior inside the group and with respect to the other group. We analyze if belonging to a participatory institution (cooperative) has a differential effect on the contributions inside the group compared to farmers selling to private mills. Common to both types of group are the social interactions at the buying point but they differ with respect to the management of the institution. An obvious concern when considering the two samples is that the two groups are not randomly assigned. It needs to be noted that in all the locations where the study was performed there were buying points of both types of mills. Table 1 presents the descriptive statistics for both samples. Farmers selling to the private market are significantly younger and more likely to have other sources of income than coffee. Farmers in both samples reported to know almost all the farmers selling to the same mill buying point. In the post-experimental questionnaire, only $16 \%$ of the farmers selling to private mills reported to have never been members of a cooperative. Farmers belong to small communities, where family and social interactions are of great importance and the point of deposit for coffee is an important social and economic meeting point that is not easily changed, especially for older generations.

\section{Methods}

The experimental part of the study had two parts, as summarized in Table 2. The protocol can be found in Appendix B. All participants made choices with respect to four different incentivized choice tasks in which they had to make decisions concerning contributions to an abstract public good option. Across the tasks we varied the identity of the partners (either cooperative farmers or free market participants) and whether a 
control mechanism was available or not. No feedback was given between the tasks.

Hence, the first part of the game allows us to compare the contributions of participants depending on the background of their partners. The second part of the game allows us to study, on the one hand, the decision to introduce the control mechanism depending on the type of partners, and, on the other hand, the reaction to this mechanism (when activated) depending on the background of the other players.

In total 86 farmers participated in the study. Cooperative farmers were members of three different cooperatives $(\mathrm{N}=55)$ and private market participants were associated with two different private mills $(\mathrm{N}=31)$. To maximize the number of independent observations, participants did not participate in a simultaneous public good game but made individual decisions with respect to three hypothetical partners. Strategies of partners were drawn from previous sessions and pre-tests. This gives us a total of 86 independent observations concerning contributions to the public good.

Instructions were orally explained and a short written summary was provided (for the detailed protocol see Appendix B). Given the age range (from 21 to 76 years old) and education level of participants, great care was taken that all participants understood the decision situation and could answer control questions. It was clearly explained that all decisions were anonymous and participants received an identifying code that was linked to their decisions. It was further stressed that experimental units would be exchanged for real money at the end of the session. ${ }^{6}$ After the decision task, participants where requested to fill out a questionnaire on personal information. At the end of the session all decisions were payed out to participants and average total earnings represented approximately a half-day labor salary for participants $\left(3270 \operatorname{colones}^{7}\right)$.

\subsection{Abstract public good task without control mechanism}

Participants were presented with an incentivized questionnaire to elicit behavior in a public good type choice situation. The questionnaire format was used due to logistic constraints, not allowing for a proper experimental setup. Recent research has indeed confirmed that answers to hypothetical experimental scenarios are the best predictors of actual game behavior (Falk et al., 2015). Since answers to our incentivized questionnaire were not purely hypothetical but earnings were based on own choices, we expect answers to be even further correlated with true game behavior.

The study had two parts, as summarized in Table 2. The first part consisted of an anonymous choice task concerning investment into an abstract public good. Participants made their individual decisions and were informed that total public good production would be determined by their own choices and the strategies of three other players that had previously participated in the game. ${ }^{8}$

\footnotetext{
${ }^{6}$ Each experimental unit was worth 50 colones.

${ }^{7}$ At the moment of the study, the exchange rate was 500 colones $=1$ US dollar.

${ }^{8}$ The study consisted of five sessions conducted in the three different cooperatives and the two private mills. For each session,
} 
Each participant received an initial endowment of 10 monetary units and had to decide how many of these to transfer to a group envelope $\left(x_{i} \in\{0,10\}\right)$. Each unit transferred to the group envelope was multiplied by 1.5 by the experimenters and the individual received $1 / 4$ th of the group envelope. The payoff function for the participant was therefore:

$$
\pi_{i}=\left(10-x_{i}\right)+\frac{1.5}{4} *\left(\sum x_{j}\right)
$$

Since individual payoffs are higher if all monetary units are kept in the private envelope, own payoff maximizing individuals should never transfer units to the group envelope. ${ }^{9}$ The task was presented in neutral and abstract terms. Each farmer received two envelopes: one labeled 'personal envelope' with ten monetary units (wooden ice-cream sticks) and one empty envelope labeled 'group envelope'. Each participant had to decide how many monetary units to transfer from one envelope to the other.

Participants made decisions on two different situations in relation to the origin of the three group members who's strategies they were matched with. Strategies came either from (i) farmers being members of a cooperative or (ii) farmers that sell to private mills. In an in-subject design we can therefore compare behavior when paired with farmers that shared the same background or with farmers that belong to the other group. ${ }^{10}$ Envelopes concerning the different situations were color coded to avoid any confusion and collected by the experimenters at the end of each game. No feedback about behavior of others was given during the session.

The Nash equilibrium in the two games is independent of the background of the partners: it is always optimal to keep all the points in the individual envelope. Hence, when analyzing the differences between them we can study the different beliefs about behavior of partners of different backgrounds, and the effect of belonging to each of the groups. This exercise will allow us to analyze the cohesion inside each of the groups, cooperative and private, and their reaction to playing with partners with a different background.

\subsection{Abstract public good task with control mechanism}

In the second part we study the impact of a control mechanism that penalizes free riding and redistributes part of the collected fines to the group. ${ }^{11}$ Participants were informed that they would have to make the same decisions as in the first part; however for each game they could decide whether to add a control mechanism

strategies from previous sessions were selected and participants were shown the envelopes by these participants to remind them that these were strategies previously played. For the first session strategies from previous pilots were used.

${ }^{9}$ Typical results on public good experiments consist of contributions between $40 \%$ and $60 \%$ in one-shot games, and of a decrease of contributions to the Nash prediction of zero public good contribution in repeated games (for details see Ledyard, 1995 and Chaudhuri, 2011).

${ }^{10}$ As a control we also included a game played with the farmers present in the same session (i.e. that share the same background and were also identifiable). Data from this control game is not further discussed in this paper.

${ }^{11} \mathrm{~A}$ large literature in experimental economics has investigated the effects of central taxation of free riders (e.g. Falkinger et al., 2000) and decentralized punishment (e.g. Fehr and Gaechter, 2000) 
to the game and hence be paired with three other individuals that also had chosen to add such a mechanism. Participants that added the control mechanism had to pay a monetary cost of one point per game. The control mechanism was such that participants contributing less than the average of their group would loose some of their monetary units. To limit efficiency losses due to control, $1 / 4$ th of the collected fees were added to the public good envelope, the rest was returned to the experimenter. Implemented penalties differed across participants and were based on randomly drawn punishment strategies from previous pilot sessions. Since we wanted to study the general reaction to control, independent of knowing whether it would render free riding unprofitable, the precise penalty amount was held ambiguous and participants were informed that the mechanism was based on previous control decisions by other participants. Participants were informed that penalties would be proportional to their deviation from average contributions in the group.

This exercise will allow us to answer two questions: (1) in which situation concerning partners background are the participants more willing to activate the control mechanism? And, once control is activated, (2) in which situation does the control mechanism have a greater effect on contributions? And how does the answer to these questions vary for the two groups considered? The answer to the first question gives us a measure on the belief of the participant on the other players willingness to free ride, and the willingness to pay a cost to ensure other partners will have incentives to contribute. The answer to the second question gives a measure of how players act differently when they know free riding by others will be punished, and when they know they are playing with partners (whatever their background is) that also choose to introduce a control mechanism on the game. We will look both at how reaction to control depends on the group where the participants belong and to their previous experience with control mechanisms.

\section{Results}

We present the results following the structure of the experimental sessions. We start by analyzing the results of the public good games played with different partners' background. We continue presenting the results on the willingness to activate the control mechanism by each of the groups with respect to the different game partners, and conclude the results section with the reaction to the activation of the control mechanism on the different games played.

In the extension section, we discuss the external validity of the results by looking deeper into the cooperative participants behavior. We look at how real life behavior ('side selling') and cooperative characteristics (labels) affect their contributions and reaction to the control mechanism. 


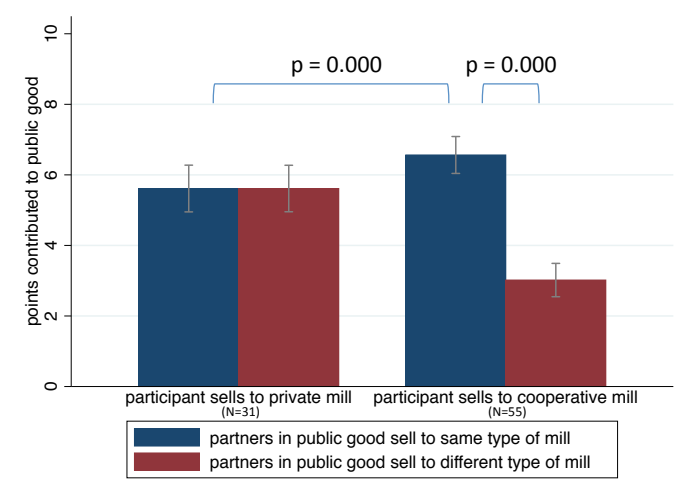

Figure 1: Contributions in public good scenario dependent on background of partners.

\subsection{Reactions to partners' background}

We start presenting how choices in the public good task are influenced by the pool from which are drawn the strategies of the three interaction partners. Cooperativists interacted either with other, unknown cooperativists or with farmers selling to private mills. We can compare this to behavior by free market participants being paired with either cooperative members or other private mill participants.

In Figure 1 we present the average contributions for each of the four games: cooperative and private mills farmers playing with their own or other background partners. Contributions to the public good when playing with participants of one's own type were $65 \%$ for cooperativists $(\mathrm{N}=55)$ and $56 \%$ for farmers selling to private mills $(\mathrm{N}=31)$, and were not statistically different (see Figure 1, Wilcoxon test, $\mathrm{p}=0.1419) .{ }^{12}$ Contributions when playing with participants from the other group were $30 \%$ for cooperativists and $56 \%$ for farmers selling to private mills. Contributions by cooperativists strongly decreased when being paired with private mill participants (Wilcoxon test, $\mathrm{p}=0.000$ ).

Result 1: In the games played with own background partners there are no significant differences across the two groups. In the games played with partners from the other group, contributions significantly decrease for cooperative farmers while are very similar for the private mills participants.

We present in Table 3 the result of the estimation of the determinants of the contributions to each of the games. We will estimate

$$
c_{i b}=\alpha+\beta * \text { PartnersBackground } b+\gamma * \text { MillType }_{i} * \text { PartnersBackground }_{b}+\delta * X_{i}+\varepsilon_{i b}
$$

\footnotetext{
${ }^{12}$ To ensure that participants understood the difference between being matched with participants that share the same background and participants that are identifiable, as shown in the order of tasks presented in Table 2, a first game was played with participants that were participating in the same session. That were therefore identifiable and from the same background. Contributions in this game were $54 \%$ for cooperativists and $54 \%$ for private market participants.
} 
where $c_{i b}$ represents contribution of individual i to the game played with own or other partners background, and $X_{i}$ is a vector of individual characteristics.

We see in Column (1) of Table 3 that there is a negative and significant effect of playing with partners of a different background, but from columns (2) to (5) we see that this result is driven by the cooperative farmers group. Cooperative farmers contribute in both games more than farmers selling to private mills, but they do contribute significantly less when the background of the partners is different from their own.

The reaction by cooperative farmers also indicates that members of cooperatives can not be categorized as 'generally' more willing to contribute to the public good. The hypothesis that both institutions provide a center of interaction among the farmers seems supported by the fact of non-different contributions towards the own group in both cases. In contrast, farmers selling to the private mills were not influenced in their behavior by the background of their partners.

Recall that cooperativists have generally always been members of a cooperative and only $31 \%$ of them have occasionally sold to a private mill (another 30\% report having sold to other cooperatives). Thus cooperativists have in general had very limited interactions with farmers selling to private mills. In contrast only $16 \%$ of private mills participants have never been part of a cooperative. The previous result thus suggests that having had previous exposure to other deposit structure influences game behavior. This is confirmed when comparing contributions by farmers (both private and cooperative) that have previously sold coffee to another sort of deposit structure to those that never did. We find that the average contribution when paired with participants from the other structure is $47 \%$ for farmers that have sold to other structures $(\mathrm{N}=43)$ versus $31 \%$ for farmers that have never done so $(\mathrm{N}=43)$ (Wilcoxon test, $\mathrm{p}=0.012)$. We discuss side-selling further in the extensions.

As robustness tests, in Table 4 we present the results clustering the standard errors at the mill level, and the interaction of the treatment (playing with different background partners) with two individual characteristics. We see that the interaction of the treatment with age and alternative sources of income is not robustly significant. These where the two individual characteristics were the samples of participants in both types of mill differed, hence we can interpret it as a test of the results being driven by the institutional characteristics of the cooperatives and not by individual characteristics.

\subsection{Introducing external control}

In the second part of the study, farmers were informed that they would make decisions concerning the same situations as encountered in the first part but that they would have the possibility to self-select into groups that either have or do not have an impartial control mechanism. This mechanism would penalize free riding 


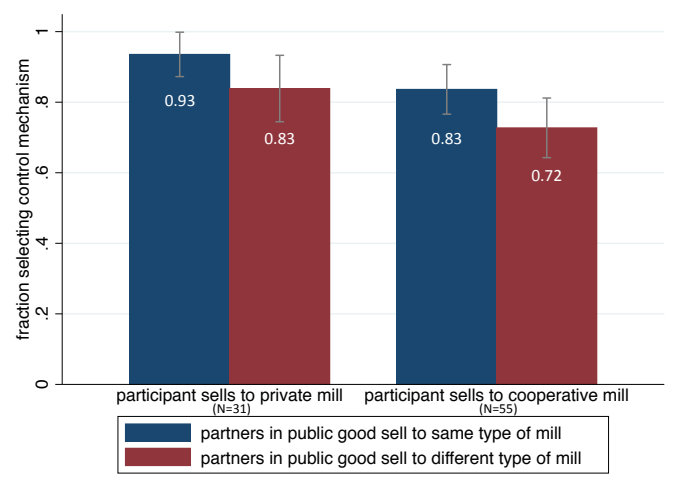

Figure 2: Decision to choose control mechanism by cooperative and private market participants dependent on background of partners.

and would redistribute part of the collected fines but had a cost to be paid by each of the farmers who decide to add the mechanism. Figure 2 shows the proportion of participants opting for the control mechanism. $83 \%$ of cooperativists opt for control when playing with other cooperativists, while $72 \%$ do so when paired with private mills participants. Cooperativists choose control less often than the private mills participants.

A concern at this point is how participants self-select into the treatment with the control mechanism. We first check whether participants that choose to introduce the control made significantly different contributions in the first games, and we can reject this being the case (Wilcoxon $\mathrm{p}=0.64$ for own group and $\mathrm{p}=0.1281$ other group, no significant effect for cooperative or private mill sellers). The only individual characteristic related to selection into control for the cooperativists when playing with sellers to private mills is their previous experience with private mills: cooperativist that reports to have sold coffee to private mills choose less often control when matched with private mills participants (Wilcoxon $\mathrm{p}=0.059$ ).

Although control is almost equally often chosen by cooperativists and by private mill participants, the effect of control on behavior in the abstract public good is significantly different for the two groups. Figure 3 shows contributions in the second part of the study when control was available and as reference we also include contribution levels from the games played when no control was available. We only consider participants that chose to add control in the second part. We see that the insurance against free riders by control has a significant effect on contributions by cooperativists, both when playing with their own type and when playing with private mills participants. The increase in contributions when playing with their own type is about $10 \%$, and the increase when playing with private mill participants is more than $100 \%$. In contrast control has no effect on contributions by private mill participants. We therefore observe the following:

Result 2: Introducing an institution that would punish free riding increases contributions by cooperativists when paired with both cooperativists and with private mill participants. 

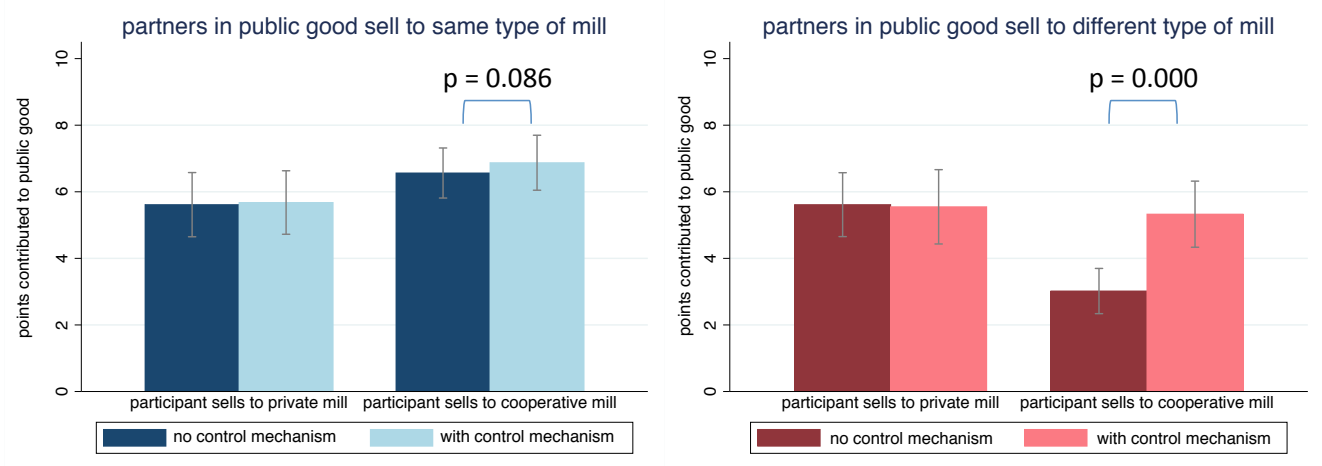

Figure 3: Contributions to Public Good when control mechanism is chosen

We proceed now to study how the control mechanism increases contributions for each of the possible partners' background. We estimate, for the games played with own and with other group partners,

$$
c_{i b}=\alpha+\beta * \text { ControlActive }_{b}+\gamma * \text { MillType }_{i} * \text { ControlActive }_{b}+\delta * X_{i}+\varepsilon_{i b}
$$

where $c_{i b}$ represents contribution of individual $\mathrm{i}$ to the game played with and without control, and $X_{i}$ is a vector of individual characteristics.

Table 5 shows the results from this estimation. We find that, when playing with own group, the introduction of a control does not have a significant effect on the contributions, and this effect is the same for both types of farmers. However, when playing with the opposite group, the introduction of the control has a significant positive effect, that is even greater for the cooperative farmers.

$$
\begin{array}{r}
c_{i b c}=\alpha+\beta_{1} * \text { PartnersBackground } d_{b}+\beta_{2} * \text { ControlActive }_{c}+\beta_{3} * \text { PartnersBackground }_{b} * \text { Control Active }_{c}+ \\
+\gamma_{1} * X_{i} * \text { PartnersBackground } \\
+\gamma_{2} * X_{i} * \text { ControlActive }_{c}+\delta * X_{i}+\varepsilon_{i t}
\end{array}
$$

where $c_{i b c}$ represents contribution of individual i to the game played with background partners $\mathrm{b}$ (own vs. other group) and with control c (not activated or activated), and $X_{i}$ is a vector of individual characteristics.

In Column (1) of Table 6 we see that the introduction of a control mechanism has a positive and significant effect on contributions, while the fact of playing with partners from the other group has a negative and significant effect. In Columns (2) to (5) we see that the interaction term between partners' background and control is positive and significant: the increase in contributions is greatest when control is introduced in the game played with the opposite group. In Columns (6) to (8) we show that this effect is mainly driven by the 
farmers selling to a cooperative mill. We proceed with a more detailed analysis of the farmers selling to a cooperative mill in the following section.

\section{Extension: Real world behavior and Cooperative's institutional characteristics}

In this section we analyze how the cooperative's institutional characteristics and the farmer's real world behavior relate to choices made in the lab. We exclusively focus on farmers that are members of a cooperative $(\mathrm{N}=55)$, recognizing that this is a rather small sample.

Cooperativists face a real world free-riding problem: financial and technical assistance from the cooperative are guaranteed by membership independently of the production and hence of the contribution to the institution. Cooperative members therefore have the possibility to benefit from the 'common services' while side-selling part or all their high quality harvest to the free market for higher prices. ${ }^{13}$ Side-selling is against cooperative rules, but punishment is very rare.

The question we would like to answer in the following, is whether self-reported side-selling is correlated with abstract public good contributions. ${ }^{14}$ We use self reports by participants concerning whether they have previously sold to mills different from their own cooperative: $61 \%$ of the cooperative farmers admit to have sold coffee out of their own cooperative (either to other cooperatives or private mills), and $31 \%$ have sold to private mills. $^{15}$

We investigate the relationship between self reported behavior and behavior in the abstract public good situation. Specifically we estimate the effect of the control mechanism for the sample of cooperative farmers when playing with other cooperativist or with private market farmers, while interacting the presence of the control mechanism with self-reported side-selling. Results are presented in Table 7. We find that side-selling has a negative effect for the contributions inside the cooperative group. However the control mechanism

\footnotetext{
${ }^{13}$ Side-selling might be an indication that farmers try to maximize their own monetary earnings, but might also be elicited by previous negative experience i.e. the observation of side-selling by others. We asked participants about their beliefs on the behavior of other cooperative members, and all participants without exception answered that they believe there are cooperative farmers that sell part of their production to the private market. As reasons they stated higher prices and the instantaneous payment received from private mills.

${ }^{14}$ For general reviews on laboratory public good games see Ledyard, 1995 and Chaudhuri, 2011. Studies confirming a relationship between abstract social dilemmas and real world free riding investigated: investment in soil and water conservation in India (Bouma et al, 2008); forest management outcomes in Ethiopia (Rustagi et al., 2010); type of fishing nets used in Brazil (Fehr and Leibbrandt, 2011); the pooling of catch for shrimp fishers in Japan (Carpenter and Seki, 2011); fishing cooperatives in Chile (Gelcich et. al., 2012). Others fail to observe such relationships: e.g. concerning forest management in Sierra Leone (Voors et al., 2011) and concerning community investment in rural Sierra Leone (Voors et al, 2012).

${ }^{15}$ We validated self reports by crossing them with information provided by the cooperative on harvests from previous years, specifically the ratio of bad (i.e. unripe) versus good coffee for the last two years prior to the present study. Selling part of one's good coffee to the private market will increase the percentage of unripe coffee delivered to the cooperative. Self reported cheaters show a 0.8 percent increase in unripe coffee over the last two years, while others show only an increase of 0.03 percent. This difference is statistically significant (Wilcoxon test, $\mathrm{p}=0.089$ ) and rather large given the ICAFE limit of $3 \%$ for unripe coffee.
} 
increases contributions of this side-selling group mainly when playing with private market participants.

While all cooperatives share by law the same regulation with respect to the rights and responsibilities of members, labels may have an additional effect on the dynamics inside the institution. We center on the most common label for coffee cooperatives: Fair Trade. ${ }^{16}$ The Fair Trade label has costs, in terms of rules to be followed (e.g. labor or environmental conditions) and benefits (e.g. primes distributed at the cooperative assembly). It needs to be noted thought that the Fair Trade certification has norms that are loosely defined, which generally apply to the cooperative as a whole. Individual punishment is thus not possible and noncompliance rarely penalized. We hypothesize that farmers exposed to the Fair Trade certification might have had negative experiences with respect to rule implementation, namely that rules can be easily bent and that individual behavior does not lead to penalties.

We concentrate on farmers belonging to cooperatives holding the Fair Trade label. We find that these farmers contribute significantly less independently of the background of their partner, but show no significant difference with respect to the control mechanism (Table 8). Unfortunately our data does not allow us to answer whether this indicates causation or is due to the self selection of certain cooperatives into the label.

\section{Conclusion}

While cooperatives are often viewed as institutional structures that enforce social and fair behavior, scientific evidence of the existence of such effects is scarce. In this study we investigated behavior in an abstract, laboratory public good situation, contrasting in particular the contributions of cooperative members to the behavior of farmers selling to private mills when paired with members of their own group versus members of different background. Our results show that members of a cooperative do not cooperate more when paired with their own type compared to free market participants. By contrast cooperative members show high distrust concerning free market participants. Thus we find no evidence that cooperative members are generally more cooperative in an abstract, anonymous dilemma. We further find evidence that cooperative members would be willing to cooperate more in such games if free riding would be penalized through some independent authority. This result is in line with findings by Gelcich et al. (2012) that show that especially members of fishing unions that have rather low performance profit from an external control mechanism. This stresses the importance of well defined and functional control mechanisms to prevent deterioration of beliefs in cooperatives. Our findings hint that collaborative behavior among farmers selling to a mill is independent

\footnotetext{
${ }^{16}$ The literature has so far failed to establish a clear positive effect of the Fair Trade certification. See for example Ronchi (2006), Philpott et. al. (2007), Arnould et.al. (2009), Pay (2009) and Blackman and Rivera (2010) for surveys; and Becchetti and Constantino (2006), Calo and Wise (2005) and Wollni and Zeller (2007) for case studies. Dragusanu and Nunn (2013) link Costa Rican household data to certifications and find no evidence that the majority of workers benefit from holding the Fair Trade certificate.
} 
of the type of mill to which they sell. But it is found that cooperative mill participants do have a significantly lower collaborative behavior when paired with private mill farmers, while private mill farmers do not make a difference between the different types of farmers. 


\section{References}

Arnould, E., Plastina, A. and Ball, D. (2009). Does fair trade deliver on its core value proposition? Effects on income, educational attainment, and health in three countries. Journal of Public Policy and Marketing, 28(2), 186-201.

Banerjee, A., Mookherjee, D., Munshi, K. and Ray, D.(2001) Inequality, Control Rights, and Rent Seeking: Sugar Cooperatives in Maharashtra Journal of Political Economy 109, 138 - 190

Banuri, S. and Keefer, P. (2012). Pro-social behavior where we least expect it? The selection and socialization of intrinsically-motivated government (tax!) officials. Working paper.

Becchetti, L. and Costantino, M. (2006). The effects of fair trade on marginalised producers: an impact evaluation on Kenyan farmers. ECINEQ Working paper.

Bernhard, H., Fehr, E. and Fischbacher, U. (2006). Group Affiliation and Altruistic Norm Enforcement, American Economic Review, 96 (2): 217-221.

Blackman, A. and Rivera, J. (2010). The evidence base for environmental and socioeconomic impacts of 'sustainable' certification. Environment for Development Working Paper.

Bouma, J., Bulte, E., van Soest, D., (2008). Trust, trustworthiness and cooperation: social capital and community resource management. Journal of Environmental Economics and Management, 56: 155166.

Calo, M. and Wise, T. (2005). Reevaluating peasant coffee production: Organic and fair trade markets in Mexico. GDAE Working paper.

Carpenter, J. and Seki, E. (2011). Do social preferences increase productivity? Field experimental evidence from fishermen in Toyama Bay. Economic Inquiry, 49(2): 612-630.

Casaburi, L. and Macchiavello, R. (2015). Loyalty, Exit and Enforcement: Evidence from a Kenya Dairy Cooperative. American Economic Review: Papers and Proceedings

Conley, T., and Udry, C. (2010). Learning about a New Technology: Pineapple in Ghana. American Economic Review 100(1): 35-69.

Chaudhuri, A. (2011). Sustaining cooperation in laboratory public goods experiments: a selective survey of the literature. Experimental Economics, 14(1): 47-83.

Dragusanu, R. and Nunn, N. (2013). The Impacts of Fair Trade Certification: Evidence From Coffee Producers in Costa Rica. working paper.

Falk, A., A. Becker, T. Dohmen, D. Huffman and U. Sunde (2015). An Experimentally-Validated Survey Module of Economic Preferences. working paper.

Falkinger, J., E. Fehr, S. Gaechter and R. Winter-Ebmer (2000). A Simple Mechanism for the Efficient 
Provision of Public Goods: Experimental Evidence, The American Economic Review, 90(1), 247-264.

Fafchamps, M. and S. Lund (2003) Risk-sharing networks in rural Phillipines Journal of Development Economics, 71, 261-287.

Fehr, E. and Leibbrand, A. (2011). A field study on cooperativeness and impatience in the tragedy of the commons. Journal of Public Economics, 95(9): 1144-1155.

Fehr, E. and S. Gchter (2000). Cooperation and Punishment in Public Goods Experiments, The American Economic Review, 90(4), 980-994.

Gelcich, S., Guzman, R.A., Rodriguez-Sickert, C., Cardenas, J.C. and Castilla J. (2012). External validity in common pool resource economic experiments: Lessons from co-managed artisanal benthic fisheries in Chile. working paper.

Goette, L., Huffman, D. and Meier, S. (2006). The impact of group membership on cooperation and norm enforcement: Evidence using random assignment to real social groups, American Economic Review, 96(2): 212-216.

Haight, C. (2011). The problem with Fair Trade coffee. Stanford Social Innovation Review.

Karlan, D., Osei, R. , Osei-Akoto, I. Udry, C. (2014) Agricultural Decisions after Relaxing Credit and Risk Constraints Quarterly Journal of Economics 597 - 652. doi:10.1093/qje/qju002.

Karlan, D. (2005). Using Experimental Economics to Measure Social Capital and Predict Financial Decisions American Economic Review 95(5), 1688-1699.

Karlan, D., M. Mobius, T. Rosenblat, and A. Szeidl (2009). Trust and Social Collateral. Quarterly Journal Of Economics 124, 1307 - 1361.

Ledyard, O. (1995). Public goods: some experimental results. In J. Kagel \& A. Roth (Eds.), Handbook of experimental economics. Princeton: Princeton University Press.

Paige, J. (1997). Coffee and Power. Harvard University Press

Pay, E. (2009). Increasing incomes and food security of small farmers in West and Central Africa through exports of organic and fair-trade tropical products. FAO Trade and Markets Division.

Philpott, S., Bichier, P., Rice, R. and Greenberg, R. (2007). Field-testing ecological and economic benefits of coffee certification programs. Conservation Biology, 21(4): 975-985.

Ronchi, L. (2006). 'Fairtrade' and market failures in agricultural commodity markets. World Bank Policy Research Working Paper, 4011.

Rustagi, D., Engel, S. and Kosfeld, M. (2010). Conditional cooperation and costly monitoring explain success in forest commons management. Science, 330: 961-965.

Simons, R. and Birchall, J. (2008). The role of co-operatives in poverty reduction: Network perspectives. The Journal of Socio-Economics, $37,2131-2140$. 
Sukhtankar, S. (2015). Does Firm Ownership Structure Matter? Evidence from Sugar Mills in India. Working paper

Sukhtankar, S. (2012). Sweetening the Deal? Political Connections and Sugar Mills in India AEJ: Applied Economics 4 (3), 43-63.

Tajfel, H. and Turner, J. C. (1975). An integrative theory of intergroup conflict, in W. G. Austin and S. Worchel, eds., The social psychology of intergroup relations, Brooks/Cole, pp. 34-47.

Voors, M., Turley, T., Kontoleon, A., Bulte, E. and List, J. (2012). Exploring whether behavior in contextfree experiments is predictive of behavior in the field: Evidence from lab and field experiments in rural Sierra Leone. Economics Letters, 114: 308-311.

Voors, M., Turley, T., Kontoleon, A., Bulte, E. and List, J. (2011). Using artefactual field experiments to learn about the incentives for sustainable forest use in developing economies. American Economic Review. Papers and proceedings, 101: 329-333.

Wollni, M. and Zeller, M. (2007). Do farmers benefit from participating in speciality markets and cooperatives? The case of coffee marketing in Costa Rica. Agricultural Economics, 37(2-3): 243-248. 
Table 1: Summary statistics of participants

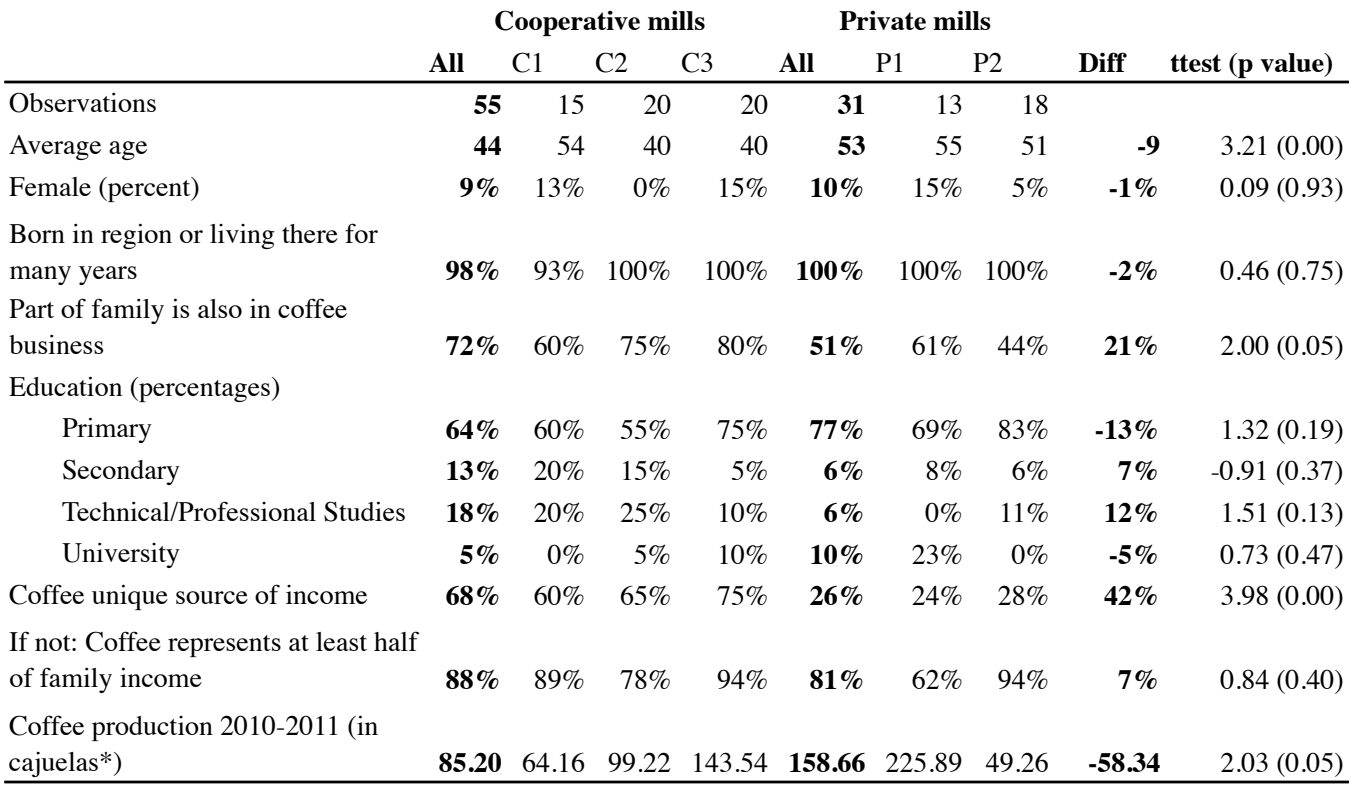

* one cajuelas is approximately equal to 4 pounds of roasted coffee

Table 2: Order of tasks during laboratory study

part 1: public good choices

0 . game played with players in same session (results not discussed in this paper)

1. hypothetical scenario with members of a cooperative

2. hypothetical scenario with free market participants

part 2: control mechanism

Choice of control:

0 . choice of control mechanism for game played with participants in same session

1. choice of control mechanism for hypothetical scenario with members of a cooperative

2. choice of control mechanism for hypothetical scenario with free market participants

Public good choices:

0. game played with players in same session (with or without control mechanism as chosen above)

1. hypothetical scenario with members of a cooperative (with or without control mechanism as chosen above)

2. hypothetical scenario with free market participants (with or without control mechanism as chosen above)

Final questionnaire

Note: Order of events was the same in all sessions and no information on contributions was announced until the end of the experiment. 
Table 3: Contributions to public good as function of background of others Dependent variable: contribution to public good game out of 10 points

\begin{tabular}{|c|c|c|c|c|c|}
\hline & $(1)$. & $(2)$. & (3). & (4). & (5). \\
\hline Treatment: & $-2.267 * * *$ & 0 & 0 & 0 & 0 \\
\hline Other group members different background & $(0.434)$ & $(0.609)$ & $(0.614)$ & $(0.629)$ & $(0.861)$ \\
\hline Cooperative member & & $\begin{array}{c}0.951 \\
(0.604)\end{array}$ & $\begin{array}{l}1.478^{*} \\
(0.749)\end{array}$ & $\begin{array}{l}1.536^{* *} \\
(0.712)\end{array}$ & $\begin{array}{l}-0.727 \\
(0.563)\end{array}$ \\
\hline Treatment $*$ Cooperative member & & $\begin{array}{c}-3.545^{* * * *} \\
(0.796)\end{array}$ & $\begin{array}{c}-3.545 * * * \\
(0.803)\end{array}$ & $\begin{array}{c}-3.472 * * * \\
(0.823)\end{array}$ & $\begin{array}{c}-3.545 * * * \\
(1.126)\end{array}$ \\
\hline Constant & $\begin{array}{c}6.221 * * * \\
(0.297) \\
\end{array}$ & $\begin{array}{c}5.613 * * * \\
(0.471) \\
\end{array}$ & $\begin{array}{c}5.462 * * * \\
(0.623) \\
\end{array}$ & $\begin{array}{c}6.650 * * * \\
(1.357) \\
\end{array}$ & $\begin{array}{c}7.500^{* * * *} \\
(0.431) \\
\end{array}$ \\
\hline Observations & 172 & 172 & 172 & 168 & 172 \\
\hline Individual Ids & 86 & 86 & 86 & 84 & 86 \\
\hline R-squared & 0.143 & 0.241 & 0.247 & 0.257 & 0.638 \\
\hline Individual FE & $\mathrm{N}$ & $\mathrm{N}$ & $\mathrm{N}$ & $\mathrm{N}$ & $\mathrm{Y}$ \\
\hline Individual controls & $\mathrm{N}$ & $\mathrm{N}$ & $\mathrm{N}$ & $\mathrm{Y}$ & $\mathrm{N}$ \\
\hline Mill FE & $\mathrm{N}$ & $\mathrm{N}$ & $\mathrm{Y}$ & $\mathrm{Y}$ & $\mathrm{Y}$ \\
\hline
\end{tabular}

Robust standard errors in parentheses (cluster individual): $* * * p<0.01, * * p<0.05, * p<0.1$

Individual controls: Age, gender, born in the town, other incomes than coffee, education. 
Table 4: Robustness checks for contributions in function of partners' background

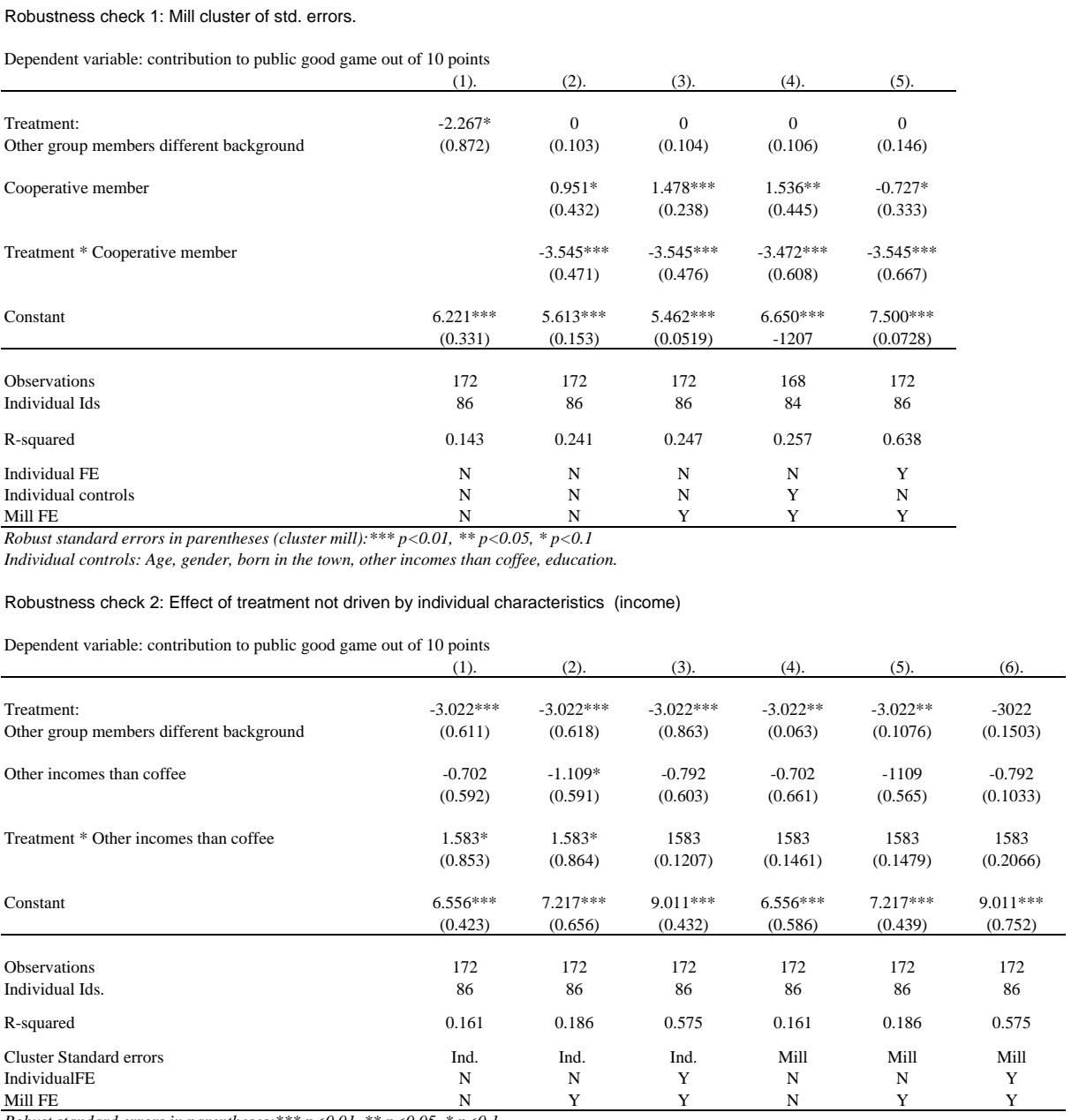

Robustness check 3: Effect of treatment not driven by individual characteristics (age)

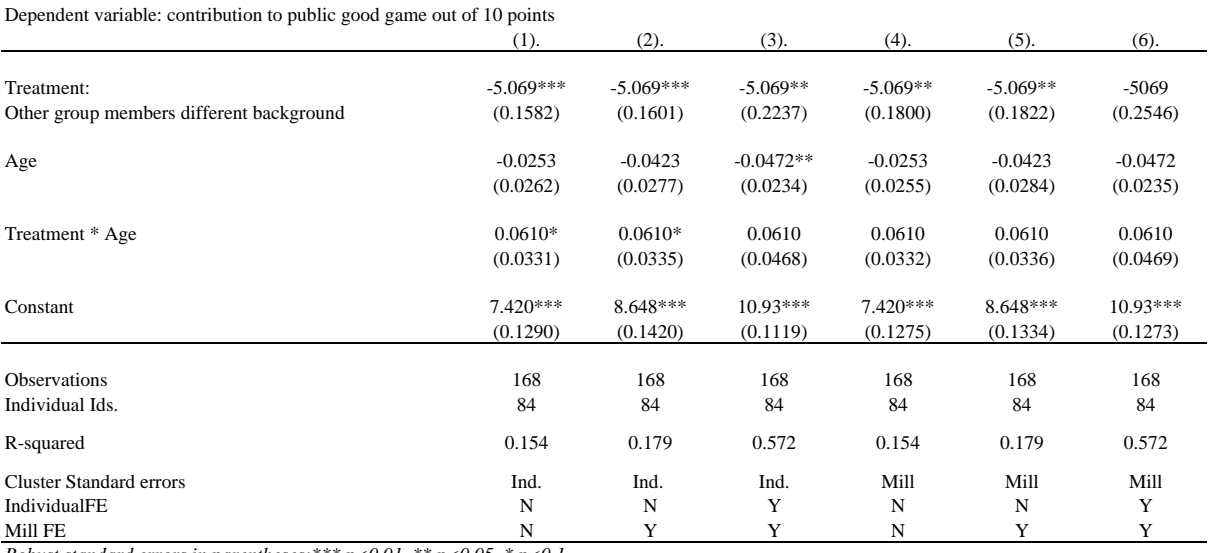

Robust standard errors in parentheses: *** $p<0.01, * * p<0.05, * p<0.1$ 
Table 5: Contributions to public good when playing with (A) own group and (B) other group, dependent on control being active

\begin{tabular}{|c|c|c|c|c|c|c|}
\hline \multicolumn{7}{|c|}{ Dependent variable: contribution to public good game out of 10 points } \\
\hline & (1). & $(2)$ & (3). & (4). & (5). & (6). \\
\hline Treatment: & 0.547 & 0.696 & 0.696 & 0.705 & 0.705 & 0.705 \\
\hline Introduction of control & $(0.336)$ & $(0.498)$ & $(0.503)$ & $(0.705)$ & $(0.530)$ & $(0.536)$ \\
\hline \multirow[t]{2}{*}{ Private mill } & & -1048 & -1654 & $-1.307 * * *$ & -0.534 & -1371 \\
\hline & & $(0.661)$ & $(1.052)$ & $(0.438)$ & $(0.651)$ & $(0.953)$ \\
\hline \multirow{2}{*}{\multicolumn{2}{|c|}{ Treatment $*$ Private mill }} & -0.385 & -0.385 & -0.385 & -0.394 & -0.394 \\
\hline & & $(0.619)$ & $(0.626)$ & $(0.876)$ & $(0.649)$ & $(0.657)$ \\
\hline \multirow[t]{2}{*}{ Constant } & $6.160 * * *$ & $6.565 * * *$ & $7.152 * * *$ & $9.652 * * *$ & $7.959 * * *$ & $9.764 * * *$ \\
\hline & $(0.331)$ & $(0.432)$ & $(0.665)$ & $(0.352)$ & $(1.509)$ & $(1.821)$ \\
\hline \multirow{2}{*}{$\begin{array}{l}\text { Observations } \\
\text { Individual IDs }\end{array}$} & 150 & 150 & 150 & 150 & 146 & 146 \\
\hline & 75 & 75 & 75 & 75 & 73 & 73 \\
\hline R-squared & 0.009 & 0.055 & 0.065 & 0.745 & 0.092 & 0.117 \\
\hline \multirow{3}{*}{$\begin{array}{l}\text { Individual FE } \\
\text { Individual controls } \\
\text { Mill FE } \\
\end{array}$} & $\mathrm{N}$ & $\mathrm{N}$ & $\mathrm{N}$ & $\mathrm{Y}$ & $\mathrm{N}$ & $\mathrm{N}$ \\
\hline & $\mathrm{N}$ & $\mathrm{N}$ & $\mathrm{N}$ & $\mathrm{N}$ & $\mathrm{Y}$ & $\mathrm{Y}$ \\
\hline & $\mathrm{N}$ & $\mathrm{N}$ & $\mathrm{Y}$ & $\mathrm{Y}$ & $\mathrm{N}$ & Y \\
\hline \multicolumn{7}{|l|}{ (B) } \\
\hline \multicolumn{7}{|c|}{ Dependent variable: contribution to public good game out of 10 points } \\
\hline & $(1)$. & $(2)$ & (3). & (4). & (5). & (6). \\
\hline Treatment: & $1.803 * * *$ & $3 * * *$ & $3 * * *$ & $3 * * *$ & $3.051 * * *$ & $3.051 * * *$ \\
\hline Introduction of control & $(0.463)$ & $(0.622)$ & $(0.630)$ & $(0.880)$ & $(0.649)$ & $(0.657)$ \\
\hline \multirow[t]{2}{*}{ Private mill } & & $2.340 * * *$ & $2.321 *$ & $4.019 * * *$ & $1.920 * *$ & 1924 \\
\hline & & $(0.663)$ & $(1.222)$ & $(0.570)$ & $(0.854)$ & $(1.227)$ \\
\hline \multirow{2}{*}{\multicolumn{2}{|c|}{ Treatment $*$ Private mill }} & $-3.038 * * *$ & $-3.038 * * *$ & $-3.038^{* * *} *$ & $-3.090 * * *$ & $-3.090 * * *$ \\
\hline & & $(0.806)$ & $(0.816)$ & (1.140) & $(0.834)$ & $(0.844)$ \\
\hline \multirow[t]{2}{*}{ Constant } & $4.197 * * *$ & $3.275^{* * *}$ & $3.615^{* * * *}$ & $3.500 * * *$ & $4.933 * * *$ & $6.259 * * *$ \\
\hline & $(0.353)$ & $(0.422)$ & $(0.753)$ & $(0.440)$ & $(1.642)$ & (2.221) \\
\hline \multirow{2}{*}{$\begin{array}{l}\text { Observations } \\
\text { Individual IDs }\end{array}$} & 132 & 132 & 132 & 132 & 130 & 130 \\
\hline & 66 & 66 & 66 & 66 & 65 & 65 \\
\hline R-squared & 0.082 & 0.155 & 0.167 & 0.705 & 0.237 & 0.252 \\
\hline \multirow{3}{*}{$\begin{array}{l}\text { Individual FE } \\
\text { Individual controls } \\
\text { Mill FE }\end{array}$} & $\mathrm{N}$ & $\mathrm{N}$ & $\mathrm{N}$ & $\mathrm{Y}$ & $\mathrm{N}$ & $\mathrm{N}$ \\
\hline & $\mathrm{N}$ & $\mathrm{N}$ & $\mathrm{N}$ & $\mathrm{N}$ & $\mathrm{Y}$ & $\mathrm{Y}$ \\
\hline & $\mathrm{N}$ & $\mathrm{N}$ & $\mathrm{Y}$ & $\mathrm{Y}$ & $\mathrm{N}$ & $\mathrm{Y}$ \\
\hline
\end{tabular}


Table 6: Contributions to experimental public good Dependent variable: contribution to public good game out of 10 points

\begin{tabular}{|c|c|c|c|c|c|c|c|c|}
\hline & \multicolumn{5}{|c|}{ All participants } & \multirow{2}{*}{$\begin{array}{c}\text { Only } \\
\text { private }\end{array}$} & \multirow{2}{*}{$\begin{array}{l}\text { Only } \\
\text { coop }\end{array}$} & \multirow[t]{2}{*}{ All } \\
\hline & (1). & (2). & (3). & (4). & (5). & & & \\
\hline \multirow[t]{2}{*}{ With Control Mechanism } & $1.268 * * *$ & $0.750^{* *}$ & $0.750 * *$ & $0.745^{* *}$ & $0.750 *$ & 0.333 & $1.065^{*}$ & 0.333 \\
\hline & $(0.341)$ & $(0.349)$ & $(0.352)$ & $(0.363)$ & $(0.403)$ & $(0.413)$ & $(0.570)$ & $(0.402)$ \\
\hline \multirow[t]{2}{*}{ With Other group } & $-1.089 * *$ & $-1.607 * * *$ & $-1.607 * * *$ & $-1.618^{* * *}$ & $-1.607 * *$ & 0.250 & $-3.065 * * *$ & 0.250 \\
\hline & $(0.426)$ & $(0.530)$ & $(0.535)$ & $(0.551)$ & $(0.612)$ & $(0.796)$ & $(0.674)$ & $(0.775)$ \\
\hline \multirow[t]{2}{*}{ Control * Other group } & & $1.036^{* *}$ & $1.036^{* *}$ & $1.055^{* *}$ & $1.036^{*}$ & -0.208 & $2.032 * * *$ & -0.208 \\
\hline & & $(0.493)$ & $(0.497)$ & $(0.512)$ & $(0.569)$ & $(0.642)$ & $(0.736)$ & $(0.625)$ \\
\hline \multirow[t]{2}{*}{ Cooperative members } & & & & & & & & 1.170 \\
\hline & & & & & & & & $(0.898)$ \\
\hline \multirow[t]{2}{*}{ Control $*$ Coop. } & & & & & & & & 0.731 \\
\hline & & & & & & & & $(0.691)$ \\
\hline \multirow[t]{2}{*}{ Other group * Coop. } & & & & & & & & $-3.315^{* * *}$ \\
\hline & & & & & & & & $(1.021)$ \\
\hline \multirow{2}{*}{\multicolumn{2}{|c|}{ Control $*$ Other group $*$ Coop }} & & & & & & & $2.241^{* *}$ \\
\hline & & & & & & & & $(0.958)$ \\
\hline \multirow[t]{2}{*}{ Constant } & $5.545 * * *$ & $5.804 * * *$ & $5.836 * * *$ & $9.341 * * *$ & $8.920 * * *$ & $7.869^{* *}$ & $8.486^{* * *}$ & $8.928 * * *$ \\
\hline & $(0.358)$ & $(0.386)$ & $(0.670)$ & (1.922) & $(0.338)$ & $(3.012)$ & $(1.864)$ & $(1.858)$ \\
\hline Observations & 224 & 224 & 224 & 220 & 224 & 96 & 124 & 220 \\
\hline Individual Ids & 56 & 56 & 56 & 55 & 56 & 24 & 31 & 55 \\
\hline $\mathrm{R}$-squared & 0.076 & 0.083 & 0.094 & 0.148 & 0.468 & 0.109 & 0.311 & 0.213 \\
\hline Individual FE & $\mathrm{N}$ & $\mathrm{N}$ & $\mathrm{N}$ & $\mathrm{N}$ & $\mathrm{Y}$ & $\mathrm{N}$ & $\mathrm{N}$ & $\mathrm{N}$ \\
\hline Individual controls & $\mathrm{N}$ & $\mathrm{N}$ & $\mathrm{N}$ & $\mathrm{Y}$ & $\mathrm{N}$ & $\mathrm{Y}$ & $\mathrm{Y}$ & $\mathrm{Y}$ \\
\hline Mill FE & $\mathrm{N}$ & $\mathrm{N}$ & $\mathrm{Y}$ & $\mathrm{Y}$ & $\mathrm{Y}$ & $\mathrm{Y}$ & $\mathrm{Y}$ & $\mathrm{Y}$ \\
\hline
\end{tabular}

Robust standard errors in parentheses (cluster individual): *** $p<0.01$, ** $p<0.05$, * $p<0.1$

Individual controls: Age, gender, born in the town, other incomes than coffee, education. 
Table 7: Contributions to public good of cooperative members, controlling for self reported side selling behavior

Dependent variable: contribution to public good game out of 10 points

\begin{tabular}{|c|c|c|c|c|c|c|}
\hline \multirow[t]{2}{*}{1} & \multicolumn{3}{|c|}{ Cooperative partners } & \multicolumn{3}{|c|}{ Private market partners } \\
\hline & $(1)$. & (2). & (3). & $(1)$. & (2). & (3). \\
\hline Treatment: & 0.696 & 0.333 & 0.333 & $3 * * *$ & 0.308 & 0.308 \\
\hline Introduction of control & $(0.498)$ & $(0.740)$ & -1034 & $(0.622)$ & $(0.667)$ & $(0.931)$ \\
\hline Side selling & & 0.243 & $-2.798 * * *$ & & -1123 & $1.506 * *$ \\
\hline & & -1118 & $(0.705)$ & & $(0.751)$ & $(0.707)$ \\
\hline Treatment $*$ Side selling & & 0.595 & 0.595 & & $3.989 * * *$ & $3.989 * * *$ \\
\hline & & -1008 & -1409 & & -1014 & -1415 \\
\hline Constant & $\begin{array}{c}6.565 * * * \\
(0.432) \\
\end{array}$ & $\begin{array}{c}6.207^{* * * *} \\
-1094 \\
\end{array}$ & $\begin{array}{c}8.333 * * * \\
(0.517) \\
\end{array}$ & $\begin{array}{c}3.275 * * * \\
(0.422) \\
\end{array}$ & $\begin{array}{c}4.176^{* * * *} \\
(0.601) \\
\end{array}$ & $\begin{array}{c}3.346^{* * * *} \\
(0.466) \\
\end{array}$ \\
\hline Observations & 92 & 92 & 92 & 80 & 80 & 80 \\
\hline Individual IDs & 46 & 46 & 46 & 40 & 40 & 40 \\
\hline R-squared & 0.015 & 0.038 & 0.671 & 0.203 & 0.304 & 0.742 \\
\hline Individual FE & $\mathrm{N}$ & $\mathrm{N}$ & $\mathrm{Y}$ & $\mathrm{N}$ & $\mathrm{N}$ & $\mathrm{Y}$ \\
\hline Mill FE & $\mathrm{N}$ & $\mathrm{Y}$ & Y & $\mathrm{N}$ & $\mathrm{Y}$ & $\mathrm{Y}$ \\
\hline
\end{tabular}

Robust standard errors in parentheses (cluster individual) :*** $p<0.01$, ** $p<0.05, * p<0.1$

Sample: Cooperative participants that choose to include control when playing with own/other group respectively

Individual controls: Age, gender, born in the town, other incomes than coffee, education,

reason to join cooperative, family in coffee, perception of implication in cooperative. 
Table 8: Contributions to public good of cooperative members, controlling for cooperative having Fair Trade certifications

Dependent variable: contribution to public good game out of 10 points

\begin{tabular}{|c|c|c|c|c|c|c|}
\hline & \multicolumn{3}{|c|}{ Cooperative partners } & \multicolumn{3}{|c|}{ Private market partners } \\
\hline & (1). & (2). & (3). & (1). & (2). & (3). \\
\hline Treatment: & 0.696 & 0.167 & 0.167 & $3 * * *$ & $4.846^{* * *}$ & $4.846^{* * *}$ \\
\hline Introduction of control & $(0.498)$ & $(1.075)$ & (1.512). & $(0.622)$ & -1147 & -1611 \\
\hline \multirow[t]{2}{*}{ Fair Trade Cooperative } & & -1045 & $-2.358 * * *$ & & 1252 & $-2.632 * * *$ \\
\hline & & $(0.960)$ & $(0.855)$ & & -1049 & $(0.941)$ \\
\hline \multirow[t]{2}{*}{ Treatment * Fair Trade } & & 0.716 & 0.716 & & $-2.735 * *$ & -2735 \\
\hline & & -1215 & -1709 & & -1340 & -1883 \\
\hline Constant & $6.565^{* * *}$ & $7.417 * * *$ & $7.917 * * *$ & $3.275^{* * *}$ & $2.692 * * *$ & $5.077 * * *$ \\
\hline & $(0.432)$ & $(0.705)$ & $(0.756)$ & $(0.422)$ & $(0.849)$ & $(0.805)$ \\
\hline Observations & 92 & 92 & 92 & 80 & 80 & 80 \\
\hline Individual IDs & 46 & 46 & 46 & 40 & 40 & 40 \\
\hline R-squared & 0.015 & 0.033 & 0.671 & 0.203 & 0.254 & 0.701 \\
\hline Individual FE & $\mathrm{N}$ & $\mathrm{N}$ & $\mathrm{Y}$ & $\mathrm{N}$ & $\mathrm{N}$ & Y \\
\hline Location FE & $\mathrm{N}$ & $\mathrm{Y}$ & $\mathrm{Y}$ & $\mathrm{N}$ & $\mathrm{Y}$ & $\mathrm{Y}$ \\
\hline
\end{tabular}

Robust standard errors in parentheses (cluster individual): $* * * p<0.01$, $* * p<0.05$, $* p<0.1$

Sample: Cooperative participants that choose to include control when playing with own group

Individual controls: Age, gender, born in the town, other incomes than coffee, education,

reason to join cooperative, family in coffee, perception of implication in cooperative. 


\section{Appendix A: Experimental procedures}

Participants were recruited by announcements from their cooperative or private beneficio to participate in a scientific study. No information about the context of the experiment was made available before hand. Participants were received in meeting rooms of their cooperative or private beneficio and individually seated. Instructions were orally explained by a native Spanish speaker and short written summaries were provided. Contributions to either the private or public good were implemented by allocating small wooden sticks between two envelops marked private or public good. Different tasks were colour coded to avoid any confusion.

Upon arrival, participants were provided with a random identifier that allocated them to their seat. Each seat had a set of the written instructions. To ensure understanding instructions were read aloud and explained in great detail on a flipchart. Participants had to be able to correctly answer control questions to proceed with the study.

To ensure the understanding of the game structure, in each part participants first played a public good game with other participants in the same session (results of this game are not discussed in this paper). Then the two hypothetical decision situations were presented. In these situations the experimenter showed the envelops containing the strategies from these previous sessions to ensure that participants understood that these choices were already taken.

\section{Written summary (translated from Spanish):}

The result of this study depends on your decisions and on the decisions of 3 other participants in this project. You will never know the identity of these persons, and they will never know that they played with you. All of you will be taking the same type of decisions.

In this game you will accumulate a number of points that at the end will be exchanged into colones with the equivalence of 1 point $=50$ Colones.

\section{Part 1:}

Game 0 - with participants in same session:

Imagine the situation where you are playing with three producers in this room.

You did receive two envelopes:

- In one of the envelopes, the 'Personal Envelope', there are 10 points. These points are yours.

- The other envelope, the 'Group Envelope', is empty.

You now have to decide how many of your 10 points you want to transfer to the 'Group Envelope'. What happens if you transfer points to the 'Group Envelope'?

1. You will have less points in your 'Personal Envelope', but

2. For each point that you add to the 'Group Envelope', we will add 0.5 points.

For example:

$>$ If you transfer all 10 points, we will add 5 points and there will be 15 points in the 'Group Envelope'.

$>$ If you do not transfer any point, we will not add anything to the 'Group Envelope'

What happens with the points in the 'Group Envelope'?

- The points in the 'Group Envelope' will be distributed equally among the members of the group, including yourself. 


\section{Example:}

$>$ If there are 20 points in the 'Group Envelope', you and each of the other 3 members of the group will receive 5 points.

You will not know how many points the other participants did transfer to the 'Group Envelope', and the other participants will never know how many points you did transfer. All participants will decided how many points to transfer before knowing the choices of the other members of the group. You have one minute to transfer the number of points you want from one envelope to the other. When done, please leave the envelopes in front of you.

Game 1 - hypothetical scenario with members of a cooperative:

Now let's repeat the previous situation and imagine that you are playing with three producers who belong to a cooperative.

You did receive two envelopes:

- In one of the envelopes, the 'Personal Envelope', there are 10 points. These points are yours.

- The other envelope, the 'Group Envelope', is empty.

You now have to decide how many of your 10 points you want to transfer to the 'Group Envelope'.

Game 2 - hypothetical scenario with members from the free market:

Now let's repeat the previous situation and imagine that you are playing with three producers who sell to the private market.

You did receive two envelopes:

- In one of the envelopes, the 'Personal Envelope', there are 10 points. These points are yours.

- The other envelope, the 'Group Envelope', is empty.

You now have to decide how many of your 10 points you want to transfer to the 'Group Envelope'. 


\section{Part 2.}

Imagine now that in the game you just played there is the possibility to establish a Coordination System: a person from outside the group will be able to decide whether to penalize the players depending on their contribution to the 'Group Envelope'.

More in detail: The 'Coordinator' will look at the average contribution of the group, and he will establish a penalty to the players that contributed below this average. In other words, the 'Coordinator' will charge a fee from the players that contribute relatively little but received the benefits from other's effort. The fees will vary with the distance between the player's contribution and the average of the group.

For example:

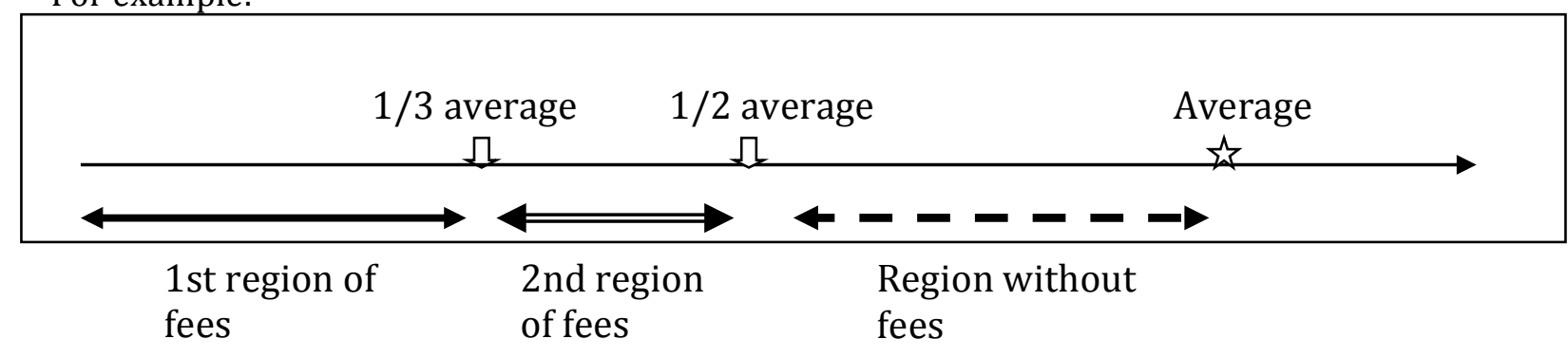

\begin{tabular}{|c|c|c|c|c|}
\hline Contribution & 0 & Average & $\begin{array}{c}\text { Less than half the } \\
\text { average }\end{array}$ & $\begin{array}{c}\text { Less than one- } \\
\text { third of the } \\
\text { average }\end{array}$ \\
\hline & & as & 2a Region of fees & 1a Region of fees \\
\hline Fees & $\square \square$ & 0 & $\square$ & $\square$ \\
\hline
\end{tabular}

To have a 'Coordinator' is costly:

- Each member of the group has to pay 1 point to the 'Coordinator' for his work.

- The 'Coordinator' receives the payment from the players (4 points), that we multiply by 1.5 ( $=6$ points), and has to return $1 / 4$ of the fees to the 'Group Envelope'. Imagine now that you are the coordinator of a group (Cooperative/Free market):

In the following table, state the contribution to the 'Group Envelope' that you consider minimal, and the punishment to the players as function of the deviation from the average.

Minimal contribution:__ points.

\begin{tabular}{|c|c|c|c|c|}
\hline Player's contribution & 0 & Average & $\begin{array}{c}\text { Less than half the } \\
\text { average }\end{array}$ & $\begin{array}{c}\text { Less than one-third } \\
\text { of the average }\end{array}$ \\
\hline Fee & & & & \\
\hline
\end{tabular}


Now we will repeat the sequence of games we did at the beginning, but before that we give you the possibility to choose if you want a coordination mechanism of not. The 'Coordinator', in case you choose one, will be a private market seller/cooperativist. The presence of a 'Coordinator' has a cost of 1 point, which will be paid by each member of the group.

Do you want to add a Coordinator (from coop / free market) to your group for game 1 (with producers in this room)?

Do you want to add a Coordinator (from coop / free market) to your group for game 2 (with members of a cooperative producers)?

Do you want to add a Coordinator (from coop / free market) to your group for game 3 (with producers selling to private market)?

Game 0 - with participants from same session:

Imagine now the situation where you're playing with three producers in this room.

- Depending on your response to the previous question, a coordinator will oversee the game.

Please decide how many of the 10 points you will transfer to the 'Group Envelop'. Please make your decision now.

Game 1 - hypothetical scenario with cooperative farmers:

Imagine now the situation where you're playing with three producers that are part of a coperative.

- Depending on your response to the previous question, a coordinator will oversee the game.

Please decide how many of the 10 points you will transfer to the 'Group Envelop'. Please make your decision now.

Game 2 - hypothetical scenario with farmers selling to free market: Imagine now the situation where you're playing with three producers that are selling to free market.

- Depending on your response to the previous question, a coordinator will oversee the game.

Please decide how many of the 10 points you will transfer to the 'Group Envelop'. Please make your decision now.

Thank you for your participation ! 


\section{Appendix B. Tables}

Table B1: Summary statistics by region and study location

\begin{tabular}{|c|c|c|c|c|c|c|c|}
\hline & \multicolumn{5}{|c|}{ Region: Tarrazú } & \multicolumn{2}{|c|}{ Region: Turrialba } \\
\hline & Total for region & Coop 1 & Coop 2 & Coop 3 & Private 2 & Total for region & Private 1 \\
\hline Number of 'poligonos' & 4940 & 366 & 784 & 735 & 665 & 1781 & 1370 \\
\hline Total extension (ha): & 33945 & 2618 & 6627 & 5886 & 3187 & 27030 & 17684 \\
\hline \multicolumn{8}{|l|}{ Use of the land: } \\
\hline Coffee & $63 \%$ & $49 \%$ & $64 \%$ & $65 \%$ & $43 \%$ & $43 \%$ & $45 \%$ \\
\hline Yearly crops & $1 \%$ & $<1 \%$ & $<1 \%$ & $<1 \%$ & $8 \%$ & $1 \%$ & $1 \%$ \\
\hline Permanent crops & $1 \%$ & $1 \%$ & $1 \%$ & $1 \%$ & $2 \%$ & $15 \%$ & $11 \%$ \\
\hline Pasto (grass for animals) & $15 \%$ & $16 \%$ & $16 \%$ & $7 \%$ & $24 \%$ & $14 \%$ & $16 \%$ \\
\hline Forest & $14 \%$ & $32 \%$ & $16 \%$ & $18 \%$ & $14 \%$ & $20 \%$ & $20 \%$ \\
\hline Other & $6 \%$ & $2 \%$ & $3 \%$ & $9 \%$ & $9 \%$ & $7 \%$ & $8 \%$ \\
\hline \multicolumn{8}{|l|}{ Principal variety of coffee planted: } \\
\hline Caturra & $87 \%$ & $57 \%$ & $81 \%$ & $90 \%$ & $89 \%$ & $89 \%$ & $88 \%$ \\
\hline Catuai & $11 \%$ & $47 \%$ & $17 \%$ & $9 \%$ & $8 \%$ & $6 \%$ & $6 \%$ \\
\hline Costa Rica-95 & $<1 \%$ & - & $<1 \%$ & $1 \%$ & $1 \%$ & $2 \%$ & $2 \%$ \\
\hline Other & $<1 \%$ & - & - & - & - & $3 \%$ & $4 \%$ \\
\hline \multicolumn{8}{|c|}{ Share of overall coffee planted by farmer's age: } \\
\hline 15 to 24 years & $25 \%$ & $5 \%$ & $11 \%$ & $20 \%$ & $22 \%$ & $<1 \%$ & $<1 \%$ \\
\hline 25 to 59 years & $50 \%$ & $74 \%$ & $66 \%$ & $60 \%$ & $53 \%$ & $65 \%$ & $67 \%$ \\
\hline More than 60 years & $23 \%$ & $25 \%$ & $22 \%$ & $18 \%$ & $25 \%$ & $3 \%$ & $24 \%$ \\
\hline \multicolumn{8}{|l|}{ Age of the plantation: } \\
\hline $0-9$ years & $13 \%$ & $14 \%$ & $13 \%$ & $20 \%$ & $14 \%$ & $19 \%$ & $21 \%$ \\
\hline $10-19$ years & $40 \%$ & $35 \%$ & $38 \%$ & $38 \%$ & $46 \%$ & $44 \%$ & $43 \%$ \\
\hline $20-29$ years & $22 \%$ & $17 \%$ & $28 \%$ & $20 \%$ & $17 \%$ & $23 \%$ & $24 \%$ \\
\hline $30-39$ years & $8 \%$ & $13 \%$ & $9 \%$ & $5 \%$ & $8 \%$ & $9 \%$ & $8 \%$ \\
\hline $40-49$ years & $4 \%$ & $6 \%$ & $3 \%$ & $2 \%$ & $4 \%$ & $3 \%$ & $2 \%$ \\
\hline more than 50 years & $3 \%$ & $1 \%$ & $2 \%$ & $1 \%$ & $1 \%$ & $2 \%$ & $2 \%$ \\
\hline missing & $9 \%$ & $15 \%$ & $7 \%$ & $14 \%$ & $10 \%$ & $1 \%$ & $1 \%$ \\
\hline \multicolumn{8}{|l|}{ Type of fertilizer (to soil): } \\
\hline Chemical & $92 \%$ & $94 \%$ & $97 \%$ & $94 \%$ & $88 \%$ & $69 \%$ & $72 \%$ \\
\hline Organic & $2 \%$ & $2 \%$ & $<1 \%$ & $<1 \%$ & $4 \%$ & $5 \%$ & $6 \%$ \\
\hline Both & $6 \%$ & $4 \%$ & $2 \%$ & $5 \%$ & $8 \%$ & $26 \%$ & $21 \%$ \\
\hline missing & $<1 \%$ & - & $<1 \%$ & $<1 \%$ & $<1 \%$ & $<1 \%$ & $<1 \%$ \\
\hline \multicolumn{8}{|l|}{ Land tenancy arrangement: } \\
\hline Owned & $96 \%$ & $100 \%$ & $100 \%$ & $99 \%$ & $98 \%$ & $95 \%$ & $94 \%$ \\
\hline Rented & $4 \%$ & $<1 \%$ & $<1 \%$ & $<1 \%$ & $2 \%$ & $4 \%$ & $5 \%$ \\
\hline Borrowed & $<1 \%$ & $<1 \%$ & $<1 \%$ & $<1 \%$ & $<1 \%$ & $<1 \%$ & $<1 \%$ \\
\hline Other & $<1 \%$ & $<1 \%$ & - & $1 \%$ & $<1 \%$ & $<1 \%$ & $1 \%$ \\
\hline \multicolumn{8}{|l|}{ Distribution of plots by size: } \\
\hline less than 1 ha & $27 \%$ & $26 \%$ & $10 \%$ & $17 \%$ & $26 \%$ & $18 \%$ & $19 \%$ \\
\hline 1 to 5 ha & $48 \%$ & $41 \%$ & $46 \%$ & $49 \%$ & $56 \%$ & $57 \%$ & $58 \%$ \\
\hline 5 to 10 ha & $12 \%$ & $12 \%$ & $18 \%$ & $18 \%$ & $8 \%$ & $13 \%$ & $13 \%$ \\
\hline 10 to 20 ha & $7 \%$ & $11 \%$ & $14 \%$ & $9 \%$ & $4 \%$ & $5 \%$ & $5 \%$ \\
\hline 20 to 50 ha & $4 \%$ & $7 \%$ & $9 \%$ & $5 \%$ & $4 \%$ & $3 \%$ & $3 \%$ \\
\hline 50 to 100 ha & $1 \%$ & $2 \%$ & $1 \%$ & $1 \%$ & $1 \%$ & $3 \%$ & $3 \%$ \\
\hline more than 100 ha & $1 \%$ & $1 \%$ & $1 \%$ & $1 \%$ & $1 \%$ & - & - \\
\hline
\end{tabular}

